\title{
While leaving abusive male partners, women engaged in a 4 stage process of reclaiming self
}

Wuest J,Merritt-Gray M. Beyond survival: reclaiming self after leaving an abusive male partner. Can J Nurs Res 2001 Mar;32:79-94.

\section{QUESTION: What are the experiences of women who have left abusive male partners and have not gone back?}

Design

Feminist grounded theory.

\section{Setting}

Small towns and rural communities in eastern Canada.

\section{Participants}

15 Caucasian women identified by lay and professional helpers as having left abusive relationships (age range: late teens to mid $50 \mathrm{y}$; education level range: elementary school to university degree; employment status: employed, students, or receiving social assistance).

\section{Methods}

All women were interviewed and initially asked to talk about how they had left their relationships. Interviews were transcribed, and concepts were identified in data analysis. Theoretical sampling and coding were used to clarify relationships between concepts and facilitate the development of a theoretical framework. In repeat interviews, emerging theories were shared with participants for discussion and refinement.

\section{Main findings}

Reclaiming self was the central social psychological process that emerged, in which women journeyed through 4 stages: counteracting abuse, breaking free, not going back, and moving on. During the counteracting abuse stage, women learned strategies for minimising abuse and building their own strengths despite sustaining painful losses. The breaking free stage was tortuous and iterative as the women tentatively drew on their increased competence, tested different exits, and discovered the consequences of leaving the relationship. During the not going back stage, women attempted to establish and protect physical and emotional territory separate from the abuser despite increased risk from escalating violence or abuse. Moving on, the fourth and longest stage, consisted of shedding the identities of victim and survivor, and of moving through the process of figuring it out, putting it in its rightful place, launching new relationships, and taking on a new image. Figuring it out was the process of searching for reasons abuse happened and why the woman remained in the relationship as long as she did. Much of the focus in figuring it out was the assignment of blame. Few sought professional help during this stage or considered the effects of social conditions, societal and cultural norms, and family traditions. Putting it in its rightful place described the process of no longer allowing the abuse experience to define their existence. They incorporated the abuse as part of their past and recognised positive consequences of relationships. Launching new relationships took place within a social environment where women were expected to be partnered (eg, sporting or social events). Women were ambivalent about launching new relationships, but over time they relaxed their criteria and expectations of new relationships. Taking on a new image was the process of leaving behind the image of abused woman or survivor and taking pride in the person they had become. Women began to take stock of themselves, recognising ways in which they were now different.

\section{Conclusion}

While leaving abusive male partners, women engaged in a 4 stage process of reclaiming self.

\section{COMMENTARY}

Few studies have explored women's experiences after leaving abusive domestic relationships. In this study, Wuest and Merritt-Gray describe the 4 stages involved in the process of reclaiming self after leaving an abusive relationship, focusing on the final stage of moving on. Profitt's feminist qualitative study of 11 women who were abused also found that women's lives were transformed after victimisation. ${ }^{1}$

When providing care, nurses need to avoid "revictimising" women who have modified their lives after domestic violence, as many will no longer see the abuse as central to their lives. Through all 4 stages of reclaiming self, nurses need to provide appropriate support through understanding; the establishment of trust; provision of community and medical resources; hope; strength; and self esteem building. Nurses must not blame women who decide to return to violent homes. Battered women repeatedly try to leave, and most eventually break free. Nurses should help women to see that abuse is not their fault. Individual and/or group counselling can assist with putting the abuse in its rightful place. However, nurses need to consider the cultural perspectives of the women they counsel. For example, Taylor found that African-American women initially preferred support groups that included other African-American women. ${ }^{2}$

The findings of this study apply to healthcare professionals who screen, assess, and treat women who are being abused or who have been abused by their intimate partners. To improve assessment and intervention strategies, healthcare providers need to identify which stage of the reclaiming self process a woman is in. When women seek health care for non-violence related issues, healthcare professionals should realise that even though women have reshaped their lives, previous feelings, thoughts, and behaviours sometimes resurface. In addition to providing care for current medical problems, healthcare professionals can validate these feelings and provide anticipatory guidance.

Sheila Harvin, RN, CS, MSN Instructor, College of Nursing Prairie View AEM University Houston, Texas, USA

1 Profitt NJ. Women survivors, psychological trauma, and the politics of resistance. New York: The Haworth Press, Inc., 2000.

2 Taylor JY. Sisters of the yam: African American women's healing and self-recovery from intimate male partner violence. Issues Ment Health Nurs 2000;21:515-31.
Fredericton, NB, Canada mmerritt@unb.ca 